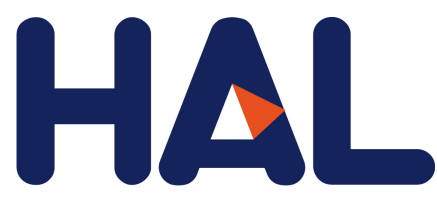

archives-ouvertes

\title{
Perceptual span, visual span, and visual attention span: Three potential ways to quantify limits on visual processing during reading
}

Aline Frey, Marie-Line Bosse

\section{- To cite this version:}

Aline Frey, Marie-Line Bosse. Perceptual span, visual span, and visual attention span: Three potential ways to quantify limits on visual processing during reading. Visual Cognition, Taylor \& Francis, 2018, pp.412-429. 10.1080/13506285.2018.1472163 . hal-01820367

\section{HAL Id: hal-01820367 \\ https://hal.archives-ouvertes.fr/hal-01820367}

Submitted on 26 May 2020

HAL is a multi-disciplinary open access archive for the deposit and dissemination of scientific research documents, whether they are published or not. The documents may come from teaching and research institutions in France or abroad, or from public or private research centers.
L'archive ouverte pluridisciplinaire HAL, est destinée au dépôt et à la diffusion de documents scientifiques de niveau recherche, publiés ou non, émanant des établissements d'enseignement et de recherche français ou étrangers, des laboratoires publics ou privés. 


\title{
Perceptual span, visual span, and visual attention span: Three potential ways to quantify limits on visual processing during reading
}

\author{
Aline Frey (10 ${ }^{a}$ and Marie-Line Bosse (1) ${ }^{b}$ \\ ${ }^{a}$ ESPE of the Créteil Academy, Chart Laboratory, University of East-Paris Creteil Val de Marne, Paris, France; ${ }^{b}$ Université Grenoble Alpes, \\ Université Savoie Mont Blanc, CNRS, LPNC, Grenoble, France
}

\begin{abstract}
Many lines of evidence have revealed limitations of the human visual system, most notably that only a portion of available information is processed in a single glance. A degree of conceptual confusion has emerged, however, regarding the underlying concepts or mechanisms explaining limited visual processing in reading; perceptual span, visual span, or visual attention span. While the original definitions of these three concepts are clear and well-differentiated, they are routinely used inconsistently in the literature. The primary goal of the present review is to respecify these three concepts in terms of what they correspond to and how they are determined. Further, we investigate whether these three spans refer to vision-related measurements and/or are based on general cognitive abilities. This review should lead to a better understanding of the involvement of visual functions in reading performance.
\end{abstract}

\section{ARTICLE HISTORY}

Received 22 August 2017

Accepted 26 April 2018

\section{KEYWORDS}

Reading; eye movements; perceptual span; visual span;

visual attention span
Reading is a highly advanced skill, which is usually acquired early in life and is used daily thereafter. Reading and its development have been studied by diverse methodological approaches for many decades and it is well-known that reading performance depends on numerous cognitive aptitudes. Specifically, a good deal of research has focused on the role of linguistic skills such as phonology, morphology, syntax, and pragmatics, which interact with each other in the processing of written language (for a review, see Gleason, 2005). More general abilities are also involved in reading, such as working memory (Silva, Faísca, Ingvar, Petersson, \& Reis, 2012), retrieval of word meaning from long-term memory (Ericsson \& Kintsch, 1995), or visual attention (Rayner, 1977; Wei \& Ma, 2016), with possible interactions between these processes.

The complex process of reading is, above all, a visual task that involves the ocular motor system. The way in which visual information is extracted from print impacts not only word recognition but also text comprehension in general. Normal reading in skilled adult subjects relies on a series of saccadic eye movements along the line of text that typically occur about four times a second. These saccades are separated by brief pauses, called fixations, during which time the eyes remain relatively stationary and visual information is acquired (for reviews, see Rayner, 1998, 2009). These fixations support the processing of details and identification of objects, effectively compensating for sensory acuity limitations of the retina. Indeed, a line of text that falls on the receptor system (e.g., the retina) can be divided into three regions: the foveal region (1 degree of visual angle on each side of fixation, which generally consists of about 6-8 letters for normal sized print), the parafoveal region (extending out to about 5 degrees and consisting of 14-15 letters from the point of fixation), and the peripheral region (everything beyond the parafovea). Because most detailed information needed for the recognition of letters and words is perceived in the foveal region, ${ }^{1}$ the reader must move their eyes to place the fovea over the part of the text to be processed (Rayner, 2014).

Thus, eye movements could potentially inform us about how much useful information is obtained per eye fixation. With recent advances in eye tracking technology, considerable attention has been devoted to the development of models of eye-movement control in text reading (for a review, see Rayner,

CONTACT Aline Frey $\otimes$ aline.frey@u-pec.fr $\Theta$ ESPE de l'Académie de Créteil, Université Paris-Est Créteil Val de Marne, Site de Livry-Gargan, 45, avenue Jean Zay, 93190 Livry-Gargan, France 
2009; Reichle, Rayner, \& Pollatsek, 2003), such as the EZ Reader (Pollatsek, Reichle, \& Rayner, 2006; Reichle, Pollatsek, \& Rayner, 2006) or SWIFT (Engbert, Nuthmann, Richter, \& Kliegl, 2005) models. The E-Z Reader model has been described as "a cognitivecontrol, serial-attention model" as it relies on two basic presumptions: first, ongoing cognitive processing, more specifically the early stage of lexical processing, controls eye movements; second, attention needed for lexical processing is allocated in a strictly serial manner, to only one word at any given time (Reichle et al., 2006). This model does not account, however, for the many effects of higher-level linguistic processes on eye movements and posits that those processes intervene in eye-movement control only when "something is wrong", thus sending a signal to stop moving forward or to execute a regression (i.e., a backward saccade to previously read text). The SWIFT model (Engbert et al., 2005) presumes that parallel processing could occur on several words at the same time (Frey et al., 2013). Another important difference between the two models is that in the SWIFT model, saccadic programmes are initiated autonomously after a variable time interval, unless this interval is extended because the word being fixated is difficult to process (Engbert, Longtin, \& Kliegl, 2002). Therefore, in contrast to the E-Z Reader model, lexical processing in SWIFT does not drive eye movements during reading; instead, saccades are initiated so as to maintain a preferred mean rate of eye movements. Apart from these differences, both models propose that reading is broadly constrained by the number of letters that can be identified in a single fixation.

Several different methods have been developed to estimate this number of letters, leading their authors to define different concepts related to the amount of information processed at a glance during reading. Thus, the concepts of visual span (VS, developed first by O'Regan, 1990, 1991) and of perceptual span (PS, developed first by Rayner and collaborators; McConkie \& Rayner, 1975; Rayner \& Bertera, 1979) were established with different paradigms, but both allow the estimation of the number of letters processed with high accuracy without moving the eyes (Legge, Ahn, Klitz, \& Luebker, 1997). More recently, the concept of visual attention span (VAS), which also refers to the number of elements processed at a glance, has been defined in line with the multi-trace memory model of word reading (Ans, Carbonnel, \& Valdois, 1998) and has been estimated with a different task from the previous two spans (Bosse, Tainturier, \& Valdois, 2007). In the literature, confusion or overlap between these different terms (VS, PS, VAS) regularly occurs. ${ }^{2}$ As an example, Pomplun, Reingold, and Shen (2001) indicated that "the term visual span has been used as a synonym of perceptual span or the span of effective vision, to refer to the region from which information was processed during fixations" (p. 57). Grainger, Dufau, and Ziegler (2016) merged these spans under the same nomenclature "span of effective vision for reading" (p. 172). Whitford and Titone (2016) spoke about PS as "also known as the attentional span" (p. 59).

However, the three spans are clearly distinguished by their authors and differ from one another, either theoretically or methodologically. The aim of this review is to clarify common features and differences between these three concepts, specifically as they relate to the quantity of information processed in a single glance during reading, and to highlight their potential relationships.

\section{Perceptual span}

PS is the first formalisation of a perceptive limitation in reading (McConkie \& Rayner, 1975, 1976). It has long been known that relatively few letters can be recognised on a line of text during a single fixation (Legge et al., 2007). A century ago, Huey (1908) mentioned a "reading range", as did Woodworth (1938) who evoked the same idea of a limited spatial area from which a reader picks up visual information. Much later, PS would be defined as the limited region from which useful information is acquired (Rayner, Slattery, \& Bélanger, 2010).

PS has been estimated with paradigms involving text reading. It was initially assessed from studies using the gaze-contingent moving window paradigm (McConkie \& Rayner, 1975; Rayner \& Bertera, 1979), in which the amount of available information provided to the reader is controlled on each eye fixation. This technique involves a virtual window which is designed to display only a part of the visual field around the fixation point, defining an area of visible text, while the letters outside this window are masked or replaced with chains of " $x$ " or random letters. The window moves in synchrony with the reader's eyes as they 


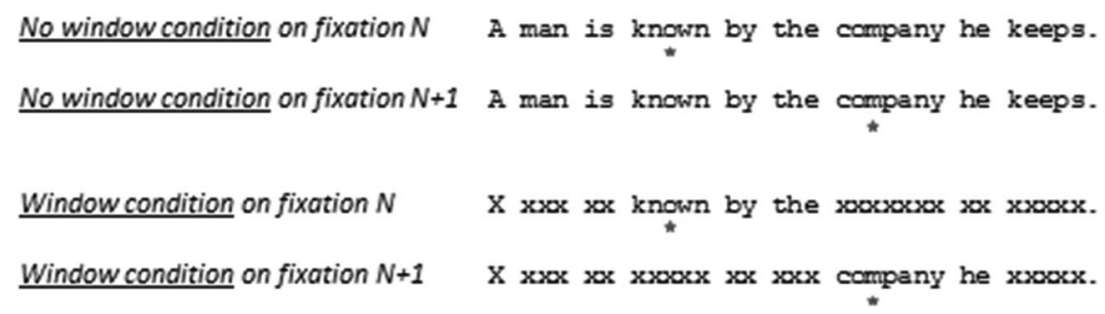

Figure 1. Example of the moving window paradigm. The asterisks indicate the position of the successive fixations. The two upper sentences represent a baseline condition in which a normal text is displayed contingent upon where the eyes are currently looking. The two lower sentences illustrate an 11-letter window in which letters outside the window are replaced by $x$.

progress along the sentence, exposing a new textual area. The pace at which these changes occur is fast enough for the reader to experience the synchronous movement of the window with their eye movements (Figure 1), and the shift of the text is generally not noticed by the subjects (Rayner, 2014). In this paradigm, eye movement measures while reading with a window, of various sizes, are compared to those while reading normally, that is, with no window. The smallest window size allowing normal reading would thus provide a valid estimate of PS. Conversely, when the window becomes smaller than the PS, reading is disrupted, especially in terms of reading rate (Rayner, Abbott, \& Plummer, 2015).

The PS paradigm measure also relies on the assumption that perceptual windows are likely to overlap across successive fixations. Research with skilled readers has demonstrated that the region of central vision around a fixation contains an overlap of information (see Rayner, 1984, for a review). However, a few studies have used alternative techniques to estimate PS under the assumption that information from succeeding fixations is non-overlapping. ${ }^{3}$

McConkie and Rayner (1976) were the first to estimate PS by varying the size of the window of visual information to the left and right of the fixation point (i.e., the window was either symmetric, left shifted, or right shifted). Their results were very clear and have been widely reproduced since: left shifted windows slow down reading, whereas symmetric and right shifted windows showed no sign of specific disruption (in languages that are read from left to right). Thus, in skilled adult readers, the region of useful visual information is asymmetric around the fixation point.

The feature of asymmetry allows information to be pre-processed from the right of the fixation point. This parafoveal preview benefit effect is robust and depends on both orthographic and phonological pre-processing involvement (Miellet \& Sparrow, 2004). By reflecting the shift in attention to upcoming words, it shows that PS in reading is modulated by attentional demands (Kliegl, Wei, Dambacher, Yan, \& Zhou, 2011). This is all the more evident when we consider that the asymmetry of the span is reversed for readers of languages written right-to-left such as Hebrew (Pollatsek, Bolozky, Well, \& Rayner, 1981), Arabic (Jordan et al., 2014), or Urdu (Paterson et al., 2014), who invariably will obtain more information from the left of the fixation than from the right. However, recent works have suggested that PS may be more symmetrical than what is commonly reported and extends much further left than previously observed. Apel, Henderson, and Ferreira (2012) used a moving-window paradigm in which they masked words beyond the four-character range to the left of a fixation. In the masked condition, they observed significantly shorter regressive saccades and longer fixation and gaze durations, but only when a regression was executed. They concluded that PS during reading depends on the direction of a following saccade. Jordan, McGowan, Kurtev, and Paterson (2016) showed that changing the normal letter content of words to the left of fixated word influenced reading performance even when this change was two words away from the fixated word (i.e., around 11 characters from the left). Along these same lines, Chung, Liu, and Hsiao (2017) used the Chinese language, that can be read from left-to-right or from right-to-left, to show that, after reading from right to left, participants showed a significantly reduced leftside bias. Overall, those results suggest that PS is more flexible and symmetrical than has previously been shown.

In English and other alphabetic languages that read from left to right, the classical gaze-contingent 
moving window paradigm has shown that PS extends from three to four letters to the left, and up to 15 letters to the right of a given fixation position to arrive at close to normal reading speed (McConkie \& Rayner, 1976). However, the extent of PS is not constant. Beyond symmetry issues evoked just before, its size is also influenced by linguistic parameters such as text readability (Rayner, 1986) and word frequency (Rayner, Liversedge, White, \& Vergilino-Perez, 2003). PS will, in fact, decrease as a function of increasing foveal processing load. Readers dynamically adjust the size of their PS because less information can be retrieved from the right of the fixation point when processing is more difficult. Indeed, the foveal-load hypothesis (Henderson \& Ferreira, 1990) proposes that PS decreases with the difficulty of the foveal word, for example, when fixating low-frequency words (Inhoff, Pollatsek, Posner, \& Rayner, 1989). A low-frequency word $n$ is assumed to narrow the focus of attention during fixation on a word, which reduces the preview benefit for word $n+1$ and leads to a smaller PS.

Individual differences have also been observed in the PS. Choi, Lowder, Ferreira, and Henderson (2015) showed that the size of a reader's PS is modulated by individual differences in language ability but not by individual differences in oculomotor processing speed, suggesting that readers with greater language proficiency are more likely to possess the necessary mechanisms for extracting linguistic information beyond the fixated word. More specifically, they observed that readers with high-level language skills showed greater processing benefit reading under the no-window condition compared to the 16-character window condition, whereas readers with lowerlevel language ability showed no additional improvement beyond the 12-character window condition. Veldre and Andrews (2014) also showed that good readers and spellers benefited from a wider rightward PS extending beyond as many as 15 characters to the right of fixation. In addition, they found that expert readers experienced more disruption with small window sizes than low-proficiency readers. On the other hand, Ashby, Yang, Evans, and Rayner (2012) and Rayner et al. (2010) found that faster readers, on average, performed better than slow readers regardless of the window size. This indicates that the size of PS appears to be specifically associated with lexical processing abilities rather than reading speed.
It has also been suggested that this size could vary according to the general "practice" in parafoveal processing: individuals with severe to profound hearing loss acquired early in life tend to have larger PSs than skilled readers with normal hearing (Bélanger, Slattery, Mayberry, \& Rayner, 2012).

PS encompasses a range of different types of information including letter features, inter-word spaces, and word length (Rayner, 1986). In this way, PS parallels the word identification span (also termed the semantic span, by Rayner \& Inhoff, 1981) in that a fixed area exists from which words can be identified during a single fixation (Ojanpää, Näsänen, \& Kojo, 2002). However, it has been demonstrated that the word identification span is smaller, measuring roughly half the size of PS. Rayner (1998) thus showed that the area from which a word can be identified extends to the left of fixation by no more than four characters, and to the right by 7-8 characters. Rayner, Well, Pollatsek, and Bertera (1982) found that the right boundary of PS is primarily defined in terms of the number of available letters, rather than available words. This indicated that PS differs from the word identification span in an important way: it clearly includes the same area where words are identified but this area is further extended to the right of fixation.

The fact that PS allows for detecting word length and inter-word spaces is significant as this information is important for oculomotor targeting (Risse, 2014). For this reason, PS has been considered a key factor in models of eye guidance during reading. O'Regan (1990) made a persuasive argument about the size of PS, by showing that its width depends on the specific type of perturbation (e.g., the position of spaces that separate words, individual letters, etc.), supporting the idea that different kinds of information can be extracted at different distances from the fixation point.

In summary, PS has been measured exclusively in the context of text reading tasks involving the interaction of numerous factors, both reader related (linguistic knowledge, age, etc.) and text content related (word and syntax difficulties, etc.). It has also been established that PS is not simply the result of acuity limitations (Miellet, O'Donnell, \& Sereno, 2009), but reflects the fact that attentional factors play a role in the acquisition of information during a fixation. 


\section{Visual span}

As was shown earlier, visual acuity decreases linearly with eccentricity. For a given letter size, it is possible to calculate the distance at which the letter size is at the acuity threshold, and then estimate the number of letters that can be fitted into the space within this eccentricity (Yu, Legge, Wagoner, \& Chung, 2014). VS has been defined as the distance on either side of the point of fixation within which characters of a given size can be recognised (O'Regan, 1990, 1991). In a reading situation, VS represents the number of adjacent letters arranged horizontally that can be recognised reliably without moving the eyes (Legge et al., 2007; Legge, Mansfield, \& Chung, 2001).

VS has mainly been measured using the trigram method, which consists of asking participants to recognise unrelated letters in trigrams (random strings of three letters) flashed briefly (e.g.,100 ms) at varying eccentricity (left and right) of a fixation point (bottom of Figure 2; see He et al., 2015). Participants are required to say aloud all three letters of the trigram (full report) in a left-to-right order, or to name only one of the three letters positioned to the left, in the middle, or to the right (partial report). Generally, after several hundred trials, the accumulated results are plotted reflecting letter identification accuracy (percent correct), as a function of the distance left and right from the fixation (top of Figure 2). It should be noted that a letter identification is considered correct only when it is reported in the right letter position, in accordance with the assumption that word recognition requires not only correct identification of the individual letters but also accurate recognition of their spatial arrangement (Yu et al., 2014). The size of VS is thus the distance (left and right) from the fixation point wherein letter recognition accuracy exceeds a level of performance of $80 \%$ correct which is expressed as the number of letters. This method captures two major properties of visual processing required for reading: letter identification and encoding the relative position of letters. It is generally considered as independent of oculomotor and topdown influences.

In normal central vision, VS is about 10 characters. Approximately five characters can be recognised to both the left and right of fixation, with above $80 \%$ accuracy. Recognition accuracy declines rapidly and monotonically for letters farther away from fixation

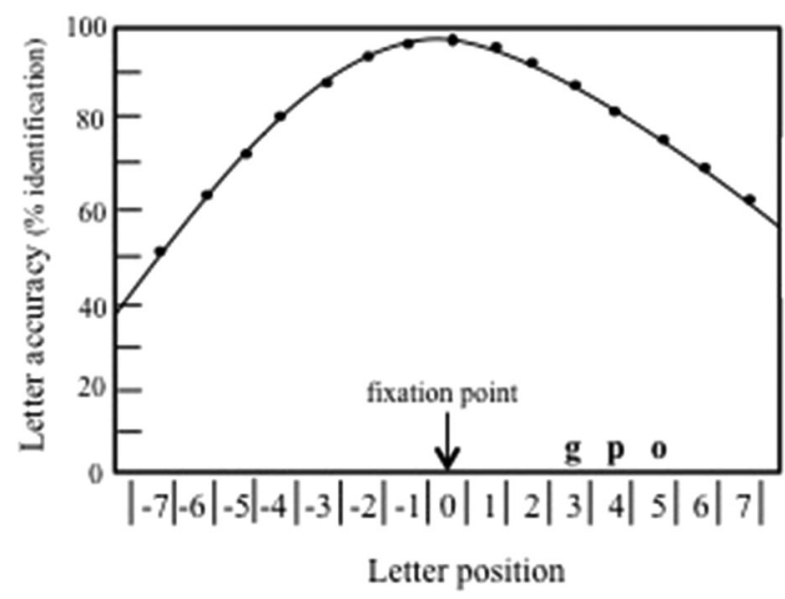

Figure 2. Example of the trigram method. Random strings of three letters are presented at specified positions to the left or right of the fixation point. A visual-span profile is a plot of letter-recognition accuracy (percent correct) as a function of letter position for data accumulated across a block of trigram trials.

than those five characters (Legge et al., 2001). It is worth noting that partial report yielded a slightly larger VS than full report using the trigram method (He et al., 2015).

Many studies have examined how the size of VS depends on attributes of printed symbols. For skilled adult readers with normal vision, manipulation of letter contrast and print size (Legge et al., 2007; Legge \& Bigelow, 2012), character spacing (Yu, Cheung, Legge, \& Chung, 2007), and orientation (i.e., vertical trigram orientation compared with conventional horizontal orientation; Yu, Park, Gerold, \& Legge, 2010) all produce major changes in the size of VS. VS is also strongly affected by crowding, a phenomenon first observed and defined by Bouma (1970). ${ }^{4}$ In his princeps experiment, Bouma measured the percent of correct recognition for letters of a fixed size, with target letters presented alone or flanked on both sides by an " $x$ " as a function of distance of the fovea. Results showed that recognition accuracy was severely reduced by the presence of flankers and that the greater the distance the flanked letter is from fixation, the more crowding results. Crowding is thus characterised by a critical minimum spacing between a target and neighbouring letters needed to allow recognition, and is an important sensory factor determining the size of VS (for a review, see Levi, 2011). To sum up, three sensory factors may constrain letter processing in VS: acuity, mislocation, and crowding. Acuity primarily limits recognition of 
isolated targets, whereas mislocation and crowding touch more directly on letter recognition within a text. Accordingly, in a study conducted by $\mathrm{Yu}$ et al. (2014), crowding accounted for $75 \%$ of lost information, whereas mislocation accounted for $19 \%$, and declining acuity away from fixation accounted for only $6 \%$.

It has been demonstrated that a strong correlation exists between the size of VS and reading speed (Legge et al., 2001; Legge et al., 2007; Legge, Hooven, Klitz, Mansfield, \& Tjan, 2002; Legge, Klitz, \& Tjan, 1997; Yu et al., 2007; Yu et al., 2010). Quantitatively, an increase of one letter recognised perfectly in VS is associated with an increase in reading speed of about 40\% (Legge et al., 2007) and regression analysis using the size of VS as a predictor indicated that $34-52 \%$ of the reading speed variability can be accounted for by the size of VS (Kwon, Legge, \& Dubbels, 2007). The role of VS size in reading speed was also incorporated into a computational model ("Mr. Chips"; Legge et al., 2002; Legge et al., 1997). In agreement with a strong relation between VS and reading speed, Pelli (2009) recently proposed a simpler measure of VS, consisting of increasing the text line length while keeping line content fixed. The underlying presumption is that participants will only need one fixation per line when the line length is less than VS, and two fixations when the line length is so long that the gap between words exceeds VS. Pelli claimed that this allows for the span to be measured quickly and easily, requiring only a printed test, a stopwatch, and an observer who can read. However, this measurement still involves linguistic factors from which VS has thus far been considered independent.

In short, VS can be represented as a small window for reliable letter recognition in the visual field. Overall, results are consistent with the idea that the size of VS is primarily determined by characteristics of early visual processing (Kwon et al., 2007). VS thus seems to reflect bottom-up sensory limitation on reading and is largely unaffected by top-down factors.

\section{Visual attention span}

Visual attention is involved in the identification of the orthographic units processed at a glance during reading and many authors have attributed a central role to the distribution of attention in processing letters and texts as a support of lexical processing (Ans et al., 1998; Bundesen, 1990, 1998; Laberge \& Samuels, 1974). VAS is the formalisation of this concept. It is defined as the number of distinct visual elements that can be processed simultaneously at a glance, in a multi-element configuration (i.e., in reading, the number of orthographic units; Bosse et al., 2007; Bosse \& Valdois, 2009). This concept was first used in the context of developmental dyslexia studies, where the VAS deficit hypothesis is still strongly debated (e.g., Goswami, 2015; Lobier \& Valdois, 2015). VAS has thus been mostly investigated in the context of reading acquisition and, to our knowledge, very few studies concern skilled adult readers (Awadh et al., 2016; Lobier, Peyrin, Le Bas, \& Valdois, 2012).

VAS has been assessed using a multi-character string report task (e.g., six uppercase letters for adults: G M V S R H). The multi-letter-strings never match the skeleton of a real word and never contain frequent bigrams or trigrams. The distance between adjacent letters is sufficient to minimise crowding. The letter-string is flashed at the centre of a screen for a short duration, generally $200 \mathrm{~ms}$. In a global report condition (Figure 3(a)), participants were asked to report verbally as many letter names as possible after their presentation, with no order constraint as the assessment only concerned the identification of letters and not position processing. In a partial report condition (Figure $3(b))$, participants were asked to report a single cued letter. The estimated VAS is the mean number of letters correctly reported in a string. Adults reported on average five letters (5.2 during the global report condition, 4.9 during the partial report condition; Valdois, Guinet, \& Embs, 2014). This paradigm was inspired by the task initially developed by Sperling (1960) and Averbach and Sperling (1968), but it differs on several critical points from this original task which was developed to estimate the maximum number of letters available in iconic memory. The main difference being that the VAS paradigm presents six spaced letters on a single row whereas Sperling used presentations of many more letters (9-12), closely spaced and presented on several rows (the only row to be reported was coded with a tone and contained 3-4 letters). With such a task, the theoretical number of letters available in iconic memory was estimated at approximately nine letters (Sperling, 1960) and could be clearly 


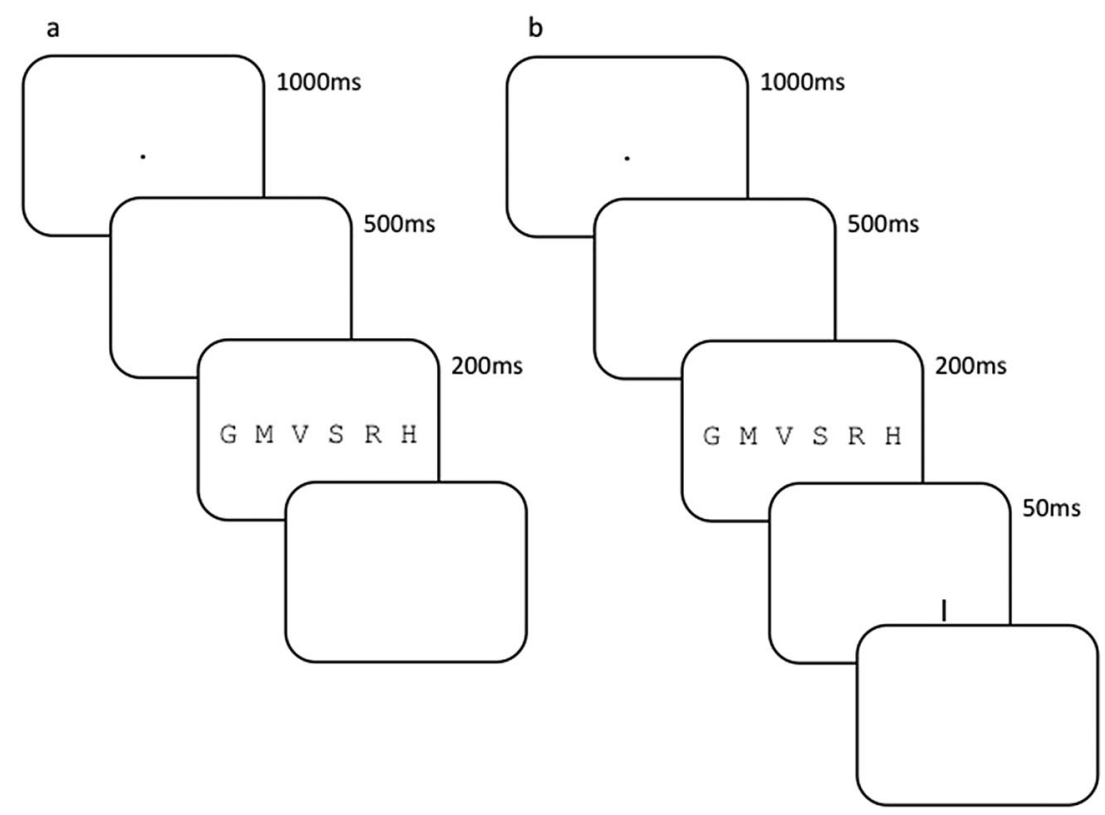

Figure 3. Multi-character string report tasks used to assess the visual attention span: (a) global report condition and (b) partial report condition.

distinguished from the number of letters that can be simultaneously processed in the VAS multi-character string report paradigm.

A second type of task related to categorisation was recently proposed to assess the same ability (simultaneous processing of multi-character strings) without using a verbal report of letters (Lobier et al., 2012; Lobier, Peyrin, Pichat, Le Bas, \& Valdois, 2014). In this case, the multi-character string is composed of characters from different categories (e.g., letters, numbers, pseudoletters, hiragana characters) and the participants were asked to report the number of characters of a target category in each string. Results showed that high verbal report performance ("classical" VAS task) is associated with high categorisation performance, regardless of the stimulus type. These different tasks and/or the kind of informational material (verbal or not) reveal the same profiles of results in terms of VAS, as well as poorer or less accurate performance in dyslexic participants (see below).

VAS has mainly been measured in normal-reading elementary school children, as well as in readingimpaired (dyslexic) children. Both individual case studies (Dubois et al., 2010; Valdois et al., 2003) and group studies (Bosse et al., 2007; Lassus-Sangosse, N'Guyen-Morel, \& Valdois, 2008; Zoubrinetzky, Bielle, \& Valdois, 2014) revealed the existence of dyslexic individuals with no apparent phonological deficit but who presented a reduced VAS, that is, a selective deficit in multi-character report tasks. Moreover, reading speed and irregular word reading performance of dyslexic children was predicted by VAS independently of phonological awareness (Bosse et al., 2007, in French and English). This was also the case in normal-reading children, where a larger VAS was found to be related to faster reading and higher irregular word reading accuracy (Bosse \& Valdois, 2009, in French; Germano, Reilhac, Capellini, \& Valdois, 2014; Sargiani, Maluf, \& Bosse, 2015, both in Brazilian Portuguese; van den Boer, van Bergen, \& de Jong, 2014, in Dutch) as well as to weaker length effects (van den Boer, de Jong, \& Haentjens-van Meeteren, 2013, in Dutch). The fact that VAS essentially affects reading speed suggests that a large VAS favours the fast whole-word procedure of reading (Lobier, Dubois, \& Valdois, 2013) and permits more letters at each fixation to be processed. It has consistently been observed that in children, a larger VAS is associated with fewer rightward fixations during text reading (Bosse, Kandel, Prado, \& Valdois, 2014; Prado, Dubois, \& Valdois, 2007). On the whole, a significant number of studies have provided evidence that VAS is an important predictor of child reading performance in both transparent and opaque alphabetic languages. In contrast, the only study to assess VAS in adult readers demonstrated a linear relationship between VAS and reading performance in 
French, but none was found in Arabic nor in Spanish (Awadh et al., 2016).

The concept of VAS is supported by the connectionist Multi-Trace-Memory (MTM) reading model (Ans et al., 1998), which posits that visual attention capacity could modulate reading performance. This model includes a visual attention window which determines the number of visual elements that are simultaneously encoded during reading. The size of the visual attention window varies according to the reading mode; VAS can be viewed as an estimation of the maximum size of this visual attention window. Implementation of this connectionist model showed that a reduction in the size of the visual attention window was particularly detrimental for familiar word processing. More recently, the importance of simultaneous processing of all the letters of a word has been highlighted by authors of other models of word identification and reading acquisition (e.g., Adelman, Marquis, \& Sabatos de Vito, 2010; Grainger et al., 2016).

VAS is modulated by language characteristics, specifically transparency ${ }^{5}$ and character complexity. When assessed in bilingual readers, namely FrenchSpanish (Lallier, Valdois, Lassus-Sangosse, Prado, \& Kandel, 2014), French-Basque, or Spanish-Basque (Lallier, Acha, \& Carreiras, 2016), individual results suggested that learning to read in two languages that differ in transparency (e.g., French-Spanish or French-Basque; French is opaque but Spanish and Basque are transparent languages) affected VAS performance differently when compared to monolingual participants or bilinguals in languages of similar transparency (e.g., Spanish-Basque). More specifically, the French-Basque bilinguals showed more efficient visual processing strategies than Spanish-Basque bilinguals when performing VAS tasks (Lallier et al., 2016). It has been well established that skilled readers of opaque languages process words as a whole, and children learning to read in opaque orthographies may preferentially try to distribute their VAS resources widely and focus on several visual elements at once (see Bosse et al., 2014). In adult skilled readers, VAS was more reduced in Arabic readers compared to French or Spanish readers (Awadh et al., 2016). More specifically, French and Spanish participants identified more letters than Arabic participants in global and partial reports, a result that could be related to the high visual complexity of Arabic characters (Ibrahim,
Eviatar, \& Aharon Peretz, 2002) and/or characteristics of the Arabic language (Perea, Mallouh, \& Carreiras, 2014; see also Lallier et al., 2018, on children reading vowelised versus non vowelised Arabic language). We could suppose that the linguistic complexity of characters (which could represent a phoneme, a syllable, or a morpheme according to the language) could also influence VAS performance and relations between attentional processes and reading (Chen, Fu, Iversen, Smith, \& Matthews, 2002; Liu, 2014), but more data on VAS in non-alphabetic languages are needed to confirm this point (see Zhao, Liu, Liu, \& Huang, 2018, for a study on VAS in a context of Chinese developmental dyslexia). Overall, these studies have shown that both letter complexity and orthographic transparency modulate VAS and, more generally, the distribution of visual attention resources in a glance.

In summary, VAS is seen as a behavioural assessment of a general visual attention process specialised for parallel processing of characters and seems to be modulated by the amount of attentional resources available (Lobier et al., 2013). A larger visual attention capacity is associated with a greater number of visual elements simultaneously processed. In reading, this determines the amount of orthographic information (letters, graphemes, syllables) that can be precisely identified during a single fixation. Thus, VAS could be a key component of reading speed increase during childhood.

\section{Perceptual span, visual span, and visual attention span: differences and similarities}

PS, VS, and VAS present similarities and differences in what they measure and in the cognitive processes they sustain. This last section sums up these commonalities and disparities.

\section{Theoretical contexts of use}

Perhaps the most upstream distinction between the three concepts, which has also to some extent contributed further to defining differences between them, is that they have been elaborated in different theoretical contexts for the purpose of answering different questions.

PS is most widely used in studies on eye-movement control in reading (where, when, and why the eyes 
move). Results of those studies have had particularly important implications for current models implementing saccade and/or fixation generation (e.g., Engbert et al., 2005), as well as towards the understanding the relationship between covert visual-spatial attention and eye-movement control (Schad \& Engbert, 2012). Overall, it is generally assumed that the linguistic information extracted from foveal vision determines when to move the eyes, while the low spatial frequency information about word spacing and letter shape extracted from the parafovea primarily determines where to move the eyes (Schotter, Angele, \& Rayner, 2012). VS focuses more on sensory bottom-up constraints on reading. According to Legge et al. (2007), the three essential factors that determine VS are peripheral acuity, crowding, and uncertainty about the relative positions of letters in strings. The VS concept is often used in studies on impaired vision (e.g., age-related macular degeneration, Cheong, Legge, Lawrence, Cheung, \& Ruff, 2008; glaucoma, Kwon, Liu, Patel, \& Girkin, 2017) or alexia (Starrfelt, Habekost, \& Leff, 2009). VAS is neither determined by crowding (because letters are spaced) nor by uncertainty about the relative positions of letters (because letters can be reported in any order). It essentially refers to the distribution of attentional resources during letter-strings processing and is particularly relevant to reading acquisition and developmental dyslexia. Notably, some dyslexic children have satisfactory phonological skills but show limitations in the number of visual elements they can process simultaneously and thus exhibit a VAS deficit (Valdois et al., 2014).

The three concepts have each been clearly defined and shown how they have been applied in different theoretical contexts for different purposes. This is a central point and emphasises the importance of avoiding further confusion or ambiguity. Nonetheless, these concepts share certain commonalities which need to be addressed. In the following section we examine potential overlaps in both their interpretation and the scope of their application.

\section{Estimated size}

One way to concretely compare the three concepts is to examine their size. PS is estimated to extend about 15 characters to the right of fixation and four characters to the left of fixation (for left to right reading

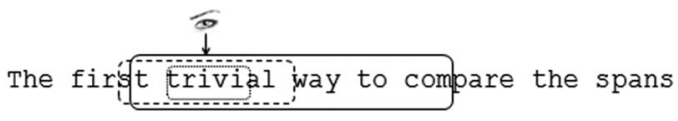

Figure 4. Size comparison of the three spans expressed in number of letters. Solid line $=$ PS; dash line $=V S$; dotted line $=$ VAS; arrow = position of eye fixation.

languages). The width of VS is around 10 characters (from left to right, i.e., five to the left and five to the right of the fixation) in individuals with normal vision. VAS is estimated to be five letters on average in adult readers. Apart from size, PS also differs from both VS and VAS in terms of asymmetry, typically showing a left-right asymmetry (according to the reading direction), whereas VS and VAS are symmetri$\mathrm{cal}^{6}$ (see Figure 4).

Beyond this simple comparison suggesting that PS is longer than VS, which in turn is larger than VAS, the question is how comparable are the conditions in which these estimations are obtained? It is likely that the estimation of these three spans depends, at least partially, on the conditions under which they are measured but may also be a function of arbitrary factors. For example, a study by Legge et al. (2001) which addressed VS underlined practical limitations involved in using the trigram method, namely due to the fact that the quoted size of VS will depend on an arbitrarily chosen accuracy criterion (e.g., VS will not be the same with a $80 \%$ accuracy or a $85 \%$ accuracy criterion). Moreover, the size of each of these spans may also depend on a combination of size of the item itself and the distance separating the item from the participant's eye. Indeed, PS has traditionally been estimated at around 19 letters under a visual condition of approximately four letters per degree of visual angle (e.g., McConkie \& Rayner, 1976). Measured in terms of the degree of visual angle instead of number of characters, PS could be estimated to be about 4.75 degrees. However, it has been reported that a slight differential in the paradigm could lead to a considerably different PS size estimation, ranging from 3 degrees (Paterson et al., 2014) to 7 degrees (Choi et al., 2015). Moreover, VS and VAS are estimated under different letter size conditions. VS is classically estimated under conditions of around two letters per degree of visual angle (e.g., Risse, 2014), while VAS is commonly estimated in a paradigm presenting around .93 letters per degree of visual angle (e.g., Bosse \& Valdois, 2009). Consequently, if the 
three spans are to be compared in terms of degrees of visual angle instead of number of letters, differences between the three become less pronounced: PS could be estimated at about 4.75 degrees (19 letters with four letters per degree in the classical paradigm of McConkie \& Rayner), VS would be about 5 degrees (10 letters with two letters per degree), and VAS would be about 4.65 degrees (five letters with .93 letters per degree). However, caution is advised before reading too much into these calculations given that the difference between a span size expressed in number of letters and a span size expressed in degrees of visual angle is by no means trivial. Indeed, several studies have suggested that the size of PS is unrelated to letter size or visual acuity (Miellet et al., 2009), while others have proposed that, for certain languages, letter size is, in fact, a determining factor (e.g., Yan, Zhou, Shu, \& Kliegl, 2015). VS was found to remain constant once reaching its maximum value with a variation in letter size ranging from $0.2^{\circ}$ to $1^{\circ}$, which only decreased for extreme letter size values (Legge et al., 2007). The size of VAS is expressed in letters but is more theoretically defined as the number of visual units (which could be larger than a single letter, for example frequent bigram or trigram graphemes) that can be simultaneously processed at a glance (Bosse \& Valdois, 2009). Taken together, these points related to size estimation show us that comparing the three concepts necessarily requires considering factors such as material and design characteristics (e.g., character size, etc.) before developing any concrete reasoning about strict quantity (expressed in either the number of letters or the degrees of visual angle). This naturally points us toward looking at the processes involved in each paradigm as a way of making a more informed comparison.

\section{Foveal vs. parafoveal processing}

The visual field can be traditionally divided in three regions: the foveal, the parafoveal, and the peripheral regions. A closer look at the role of these visual regions in the three concepts shows us that PS refers to processing of letters in both the foveal and parafoveal areas, and VS and VAS, on the contrary, essentially refers to processing of letters in the foveal area. Indeed, a large body of evidence has shown that parafoveal information from the right of the fixation is extracted and used during text reading and, consequently, also within the PS paradigm (for a review, see Rayner, 1998, 2014). This is mainly reflected in the parafoveal preview benefit, which refers to the fact that reading is slower when the word to the right of the currently fixated word is not visible than when it is visible (Blanchard, Pollatsek, \& Rayner, 1989). It would also appear that parafoveal information concerning the $N+1$ word influences processing of the currently fixated $N$ word, a so-called parafoveal-on-foveal effect (first observed by Pollatsek, Rayner, \& Balota, 1986). As we briefly referred previously, "it is probably more accurate to talk about perceptual spans rather than a single span" (Rayner, 1981, p. 152). Indeed, PS can be seen as composed of different "sub-spans" which encompass different types of information obtained from different regions. The area of PS containing information necessary for word identification (i.e., word identification span) may be rather small and therefore is in the foveal area, whereas the PS area containing parafoveal information might be considerably larger (see Figure 5).

That traditional methods of estimating both VS span and VAS span do not use visual stimuli far from the fovea could lead to the assumption that they are not dependent on peripheral visual processing. However, they both measure centred visual processing in a very different way. More precisely, the trigram method (VS, Figure 2) measures acuity distribution with respect to the distance from the fovea. It essentially refers to the spatial properties of letters recognition and to the crowding effect which increases when trigrams are positioned away from the fovea. In contrast, while the letter report tasks (VAS, Figure 3) simultaneously presented a larger number of letters, they were sufficiently spaced to avoid crowding. Thus, VAS essentially refers to the ability to distribute visual attention on a large number of letters presented on the fovea. It estimates the quantity of letters that can be processed simultaneously and that become available for subsequent high-level processing. Each span or concept could effectively be viewed as a method of estimating a different limitation of visual processing during reading (Figure 5).

\section{Bottom-up vs. top-down influences}

Cognitively, PS reflects functional demands of reading in addition to letter recognition. It brings into play 


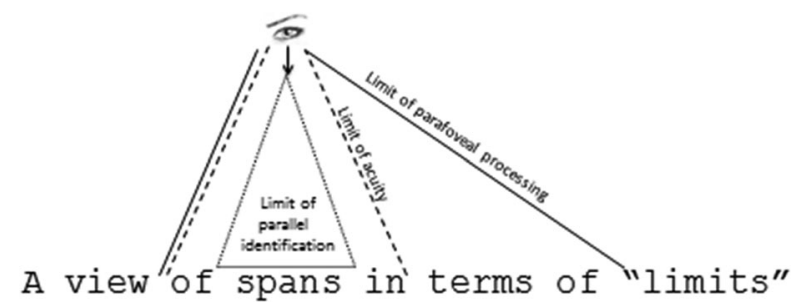

Figure 5. Representation of the three spans in terms of processing limits. Solid line =PS; dash line =VS; dotted line =VAS; arrow $=$ position of eye fixation.

lexical knowledge as well as contextual constraints, with the underlying assumption that "perception" is "vision" plus "knowledge" (O'Regan, 1990). In contrast to the two other spans, there is ample evidence that PS depends on lexical knowledge. When characters form words, letters are more easily recognised (the word-superiority effect; Baron \& Thurston, 1973) and the total span of perception increases. Another argument for the influence of top-down cognitive factors is that the size of PS was found to be dependent on text difficulty (Rayner, 1986) and word frequency (Rayner et al., 2003). Contrary to what its name suggests, PS seems poorly determined by perceptual factors, even if sensory and perceptual factors may also contribute to PS in some pathological situations, as shown in the study by Bullimore and Bailey (1995) with patients with macular degeneration. They observed shorter saccades and inferred a reduced PS, presumably linked to deficiencies of visual encoding. It has been suggested that in a larger sense, PS could principally reflect readers' linguistic processing rather than visual processing (Rayner, 1986), but the actual measurement of PS, sensitive to contextual effects, does not allow for distinctions to be made between the various perceptual and/or linguistic contributions.

In contrast to the PS paradigm, VAS and VS are based on paradigms requiring the report of isolated letters. Consequently, they are intended to be relatively independent of top-down lexical influences, with the exception of the influence of letter-name knowledge. VS is likely to be primarily determined by low-level characteristics of visual processing. In other words, it refers to what can be seen without the help of linguistic knowledge or context, whereas, as we described earlier, PS includes what can be seen with this type of support (see Jordan et al., 2014, and Paterson et al., 2014, for a new concept of "central perceptual span", a mix of both VS and PS). VS could theoretically then be viewed as a bottom-up sensory limitation on the ability to recognise letters and effectively might explain why reading slows down when retinal image contrast is low. However, as indicated in the VS section, trigram partial report leads to larger VS than full report, and this benefit may be related to changes in high-level processing, such as more focused visual attention or reduced load on working memory. Therefore, while VS essentially depicts a limitation at the sensory level, its size may be influenced by the interaction between lower- and higher-level processes ( $\mathrm{He}$ et al., 2015).

The traditional VAS paradigm also requires the report of isolated letters. That a relatively large number of letters are simultaneously presented and are spaced to avoid crowding means that VAS refers to the maximum number of letters that can be simultaneously identified. Consequently, VAS should theoretically depend essentially on the visual attention system responsible for the ability to simultaneously process letter strings. The presumption of simultaneous processing of letters during reading is factored into most reading models (e.g., McClelland \& Rumelhart, 1981; for a review, Phénix, Diard, \& Valdois, 2016; see however Whitney, 2001), which posit that in reading words, information about the identity of each letter starts to be extracted at the same time, regardless of horizontal position (Adelman et al., 2010). The finding that VAS increases with age very likely reflects an improvement of the visual attentional processing system with reading experience (Bosse \& Valdois, 2009). Table 1 sums up the different perceptive and cognitive influences that are mainly involved in the three spans.

\section{Relation with reading}

Beyond drawing comparisons between their paradigms, a parallel and pertinent question is whether

Table 1. Comparison between the three original spans in terms of the most influential underlying processing.

\begin{tabular}{|c|c|c|c|}
\hline & PS & VS & VAS \\
\hline Foveal processing & $X$ & $X$ & $\mathrm{X}$ \\
\hline Visual acuity & $x$ & $X$ & \\
\hline Parafoveal processing & $X$ & & \\
\hline Crowding between adjacent letters & & $X$ & \\
\hline Relative spatial position of letters & & $X$ & \\
\hline Simultaneous visual attention distribution & & & $\mathrm{X}$ \\
\hline Attention shifting & $X$ & & \\
\hline Letter name knowledge top-down influence & $x$ & $X$ & $\mathrm{X}$ \\
\hline Lexical knowledge top-down influence & $x$ & & \\
\hline
\end{tabular}


the three spans relate differently to reading speed or reading accuracy. A wide range of studies have shown that a correlation exists between PS and reading speed (in words per minute), and that fast readers presented a larger PS than slow readers (e.g., Ashby et al., 2012; Rayner et al., 2010). VS has also been shown to be clearly related with reading speed (e.g., Legge et al., 2007). Among others, Chung, Legge, and Cheung (2004) found that increasing VS through practice resulted in associated improvements in reading speed (derived from a rapid serial visual presentation paradigm), and is consistent with the view that VS limits sensory input on each fixation before mediating reading speed (Risse, 2014). In this sense, recent findings have highlighted the role of low-level properties in reading, particularly for spatial frequencies. Overall, results have shown that reading behaviour is closest to normal for medium and high spatial frequency displays, and less efficient for all other spatial frequencies (Jordan, Dixon, McGowan, Kurtev, \& Paterson, 2016). Further investigation is needed to specify the effectiveness of different spatial frequencies for reading and possible links between reading and VS. Regarding VAS, to our knowledge only one study (conducted for French) has reported a significant relationship between VAS abilities and reading speed in skilled adult readers (Awadh et al., 2016). VAS, however, consistently predicts reading speed (words per minute) in both normal and dyslexic children (e.g., Bosse et al., 2007; Bosse \& Valdois, 2009; Lobier et al., 2013; Zoubrinetzky et al., 2014). All three concepts, it would appear, are related to reading speed. The nature of this relation, however, is different for each concept. VS and VAS reflect sensory and attentional limitations that can directly affect reading speed. For PS, whose paradigm is dependent on reading skills, the causal relationship may be inverted (reading speed affects PS) or may be bidirectional.

Moreover, reading fast does not necessarily mean reading precisely and accurately (Perfetti, 2007), and fast readers may also adopt a strategy resulting in a lower comprehension threshold. Most studies focused on PS have addressed the issue of ensuring careful reading by taking the extra measure of instructing participants to answer to comprehension questions (e.g., "Subjects were asked a simple yes/no comprehension question at this time on $20 \%$ of the trials", p. 420, Henderson \& Ferreira, 1990; "To ensure that participants were attentive throughout the experiment, $20 \%$ of the experimental sentences were followed by yes/no comprehension questions", p. 62, Whitford \& Titone, 2016), whereas speed instruction was rarely given (e.g., "Subjects were asked to read the sentences out loud as quickly as they could without making errors", p. 592, Crossland \& Rubin, 2006). With this in mind, we could hypothesise that PS is highly related with reading accuracy and orthographic lexical representations. Accordingly, Veldre and Andrews (2014) found that reading ability (in combination with spelling ability) predicted the rightward extent of PS in skilled readers. They concluded that good orthographic lexical representations, which support rapid recognition of fixated words, also support efficient processing of parafoveal information. Thus, similar to the case of reading speed, reading accuracy could also affect PS. To our knowledge, relatively few studies have addressed the relationship between VS and reading accuracy; most of the literature focuses on the high relation between VS and reading speed. Finally, in normal and/or dyslexic children, VAS has been shown to predict reading accuracy (of both regular and irregular words; e.g., Bosse et al., 2007; Bosse \& Valdois, 2009; Zoubrinetzky et al., 2014) and orthographic knowledge (e.g., van den Boer, van Bergen, \& de Jong, 2015). Consequently, it has been suggested that VAS could affect the acquisition of lexical orthographic representations (Bosse, Chaves, Largy, \& Valdois, 2015). More studies are needed, however, to investigate this specific issue (Nation \& Castles, 2017).

\section{Neural bases}

An additional approach to further our understanding of commonalities and differences between the three spans might be to seek out their neural substrates. Unfortunately, as far as we know, very little research has been carried out in this field. A practical challenge is that PS is potentially too large a concept to be investigated at the neural level. VS has also been poorly investigated in terms of neural correlates, which may be linked to the debate concerning the inter-hemispheric activation during a word fixation (the split-fovea theory, e.g., Ellis \& Brysbaert, 2010 , vs. the bilateral projection theory, e.g., Jordan \& Paterson, 2010). In the field of neuropsychology, a case of pure alexia caused by damage to the left 
fusiform gyrus has been described, together with a deficit of VS (Starrfelt et al., 2009). Insofar as VS is dependent on crowding, we can assume that VS neural bases are potentially related, at least in part, to those of crowding which has been more widely investigated. Evidence has demonstrated that the site of crowding may be V1, V2, V3, and/or V4 (Kilho, Chung, \& Bosco, 2017), depending on the nature of the stimuli (letter, faces; Whitney \& Levi, 2011). In any case, neural bases of crowding develop at an earlier stage of visual processing which refutes theories implicating a high-level origin of crowding (Shin, Chung, \& Tjan, 2017). Finally, the neural substrate of VAS has been identified in fMRI studies, in which participants showed increased bilateral activation of the superior parietal lobe when asked to perform simultaneous multicharacter processing (Peyrin et al., 2012). In addition, a dysfunction of these brain areas has been shown in dyslexic children diagnosed with a VAS deficit (Peyrin, Démonet, N'Guyen-Morel, Le Bas, \& Valdois, 2011).

\section{Conclusion}

One of the issues that has long occupied researchers studying eye movements in reading is the question of how much is actually seen during each eye fixation. We do know that only a few letters or words of text can be recognised in a single glance, and this limitation has been referred to, more or less interchangeably, as PS, VS, or VAS. This review clearly shows that these three concepts are distinctly different, based on their attributes as paradigms and their theoretical applications, and must not be confused or used interchangeably.

The three spans are mainly distinguishable by their size, but we have highlighted the possibility that their size is dependent on the specific nature of the underlying paradigm (i.e., selection of thresholds, number of letters, degree of visual angle, etc.), which is not necessarily constant within each span. More fundamentally, differences in the theoretical conceptions that support the three spans have also been emphasised. PS mainly relies on multiple "top-down" influences, such as individual differences in reading abilities or text readability. In contrast, VS is thought to be independent of top-down influences and relies on visual acuity to capture position and identification of letters. Finally, VAS measures visual attention abilities in parallel processing of letters and thus could be considered instead as an estimation of visual attention resources limitation during a single fixation. Interestingly, despite the misleading nomenclature, PS is the one concept among the three to rely the least on perceptual input.

PS turned out to be the most prominent concept in terms of explaining spatiotemporal decisions in eyemovement control during reading. Accordingly, PS is considered the reference span for models of eye guidance during text reading, supported by underlying assumption that eye movements during reading depend on parafoveal processing. By contrast, both visual acuity and visual attention abilities in the foveal area are considered to be particularly important for efficient single word processing. In this way, both VS and VAS may be two different useful concepts to enhance models of written word processing, specifically for the first steps of visual and orthographic processing.

Despite the fact that these three concepts are measured by different tasks and sustained in different theoretical frameworks, we still can legitimately question the extent to which these three spans share, rely on, or measure perceptual and cognitive skills, both in skilled adult readers and in children (see Frey, 2016, for a review of eye movements in children during reading). To our knowledge, to date, no research has measured these three spans in a single cohort of participants. By using an identical experimental design, this type of study could address any issue of bias and would, ultimately, further our understanding of the role of visual processing in skilled reading and reading acquisition.

\section{Notes}

1. Recent findings suggested that reading performance is actually quite tolerant of substantial restrictions to the visual input available for text brought into foveal vision (i.e., coarse, medium, or fine spatial frequency content; Jordan, McGowan, \& Paterson, 2012).

2. We have also found the acceptation "visual apprehension span" (Starrfelt et al., 2009) defined as the maximum number of items that can be recognised in one view. As this term has been used in a limited context specific to literature focused on pathology (alexia), we have chosen to exclude it from this review.

3. Two additional techniques have previously been used to investigate PS: (1) dividing the number of words per line by the number of fixations per line; (2) using a 
tachistoscopic presentation of words and letters in eccentric vision. Both techniques presented significant limitations (Rayner, 1986).

4. More precisely, crowding was identified in the clinical vision literature in connection with amblyopia (Flom, Weymouth, \& Kahneman, 1963; Levi \& Klein, 1985) well before Bouma (1970), but the latter brought it to the attention of researchers interested in letter recognition and reading.

5. Alphabetic writing systems range from transparent to opaque, depending on their degree of consistency between grapheme to phoneme correspondences. A language in which each grapheme corresponds to a single phoneme is "transparent". Conversely, when each grapheme can correspond to several phonemes, the language is considered "opaque". However, the transparent/opaque dichotomy also reflects differences in the size of relevant orthographic units, and graphemes are typically shorter in more transparent languages (Awadh et al., 2016).

6. The visual span profiles tend to be slightly broader on the right than the left (Legge et al., 2001) when letters are presented within strings of other letters (crowded letters), but the recognition of isolated letters is the same in the left and the right visual field (Nazir, O'Regan, \& Jacobs, 1991).

\section{Disclosure statement}

No potential conflict of interest was reported by the authors.

\section{ORCID}

Aline Frey (D) http://orcid.org/0000-0002-0110-8633

Marie-Line Bosse (D) http://orcid.org/0000-0002-9864-380X

\section{References}

Adelman, J. S., Marquis, S. J., \& Sabatos de Vito, S. G. (2010). Letters in words are read simultaneously, not left-to-right. Psychological Science, 21(12), 1799-1801.

Ans, B., Carbonnel, S., \& Valdois, S. (1998). A connectionist multitrace memory model of polysyllabic word reading. Psychological Review, 105, 678-723.

Apel, J. K., Henderson, J. M., \& Ferreira, F. (2012). Targeting regressions: Do readers pay attention to the left? Psychonomic Bulletin \& Review, 19(6), 1108-1113.

Ashby, J., Yang, J., Evans, K. H., \& Rayner, K. (2012). Eye movements and the perceptual span in silent and oral reading. Attention, Perception, \& Psychophysics, 74(4), 634-640.

Averbach, E., \& Sperling, G. (1968). Short term storage of information in vision. In R. N. Haber (Ed.), Contemporary theory and research in visual perception (pp. 196-211). New York: Holt, Rinehart \& Winston.
Awadh, F. H. R., Phénix, T., Antzaka, A., Lallier, M., Carreiras, M., \& Valdois, S. (2016). Cross-language modulation of visual attention span: An Arabic-French-Spanish comparison in skilled adult readers. Frontiers in Psychology, 7, 307. Retrieved from https://www.ncbi.nlm.nih.gov/pmc/articles/PMC4779959/

Baron, J., \& Thurston, I. (1973). An analysis of the word-superiority effect. Cognitive Psychology, 4(2), 207-228.

Bélanger, N. N., Slattery, T. J., Mayberry, R. I., \& Rayner, K. (2012). Skilled deaf readers have an enhanced perceptual span in reading. Psychological Science, 23, 816-823.

Blanchard, H. E., Pollatsek, A., \& Rayner, K. (1989). The acquisition of parafoveal word information in reading. Perception \& Psychophysics, 46, 85-94.

Bosse, M. L., Chaves, N., Largy, P., \& Valdois, S. (2015). Orthographic learning during reading: The role of wholeword visual processing. Journal of Research in Reading, 38 (2), 141-158.

Bosse, M.-L., Kandel, S., Prado, C., \& Valdois, S. (2014). Does visual attention span relate to eye movements during reading and copying? International Journal of Behavioral Development, 38(1), 81-85.

Bosse, M.-L., Tainturier, M. J., \& Valdois, S. (2007). Developmental dyslexia: The visual attention span deficit hypothesis. Cognition, 104(2), 198-230.

Bosse, M.-L., \& Valdois, S. (2009). Influence of the visual attention span on child reading performance: A cross-sectional study. Journal of Research in Reading, 32(2), 230-253.

Bouma, H. (1970). Interaction effects in parafoveal letter recognition. Nature, 226(241), 177-178.

Bullimore, M. A., \& Bailey, I. L. (1995). Reading and eye movements in age-related maculopathy. Optometry and Vision Science, 72, 125-138.

Bundesen, C. (1990). A theory of visual attention. Psychological Review, 97, 523-547.

Bundesen, C. (1998). Visual selective attention: Outlines of a choice model, a race model and a computational theory. Visual Cognition, 5, 287-309.

Chen, Y., Fu, S., Iversen, S. D., Smith, S. M., \& Matthews, P. M. (2002). Testing for dual brain processing routes in reading: A direct contrast of Chinese character and pinyin reading using fMRI. Journal of Cognitive Neuroscience, 14(7), 10881098.

Cheong, A. M., Legge, G. E., Lawrence, M. G., Cheung, S. H., \& Ruff, M. A. (2008). Relationship between visual span and reading performance in age-related macular degeneration. Vision Research, 48(4), 577-588.

Choi, W., Lowder, M. W., Ferreira, F., \& Henderson, J. M. (2015). Individual differences in the perceptual span during reading: Evidence from the moving window technique. Attention, Perception \& Psychophysics, 77(7), 2463-2475.

Chung, H. K., Liu, J. Y., \& Hsiao, J. H. (2017). How does reading direction modulate perceptual asymmetry effects? The Quarterly Journal of Experimental Psychology, 70(8), 15591574.

Chung, S. T. L., Legge, G. E., \& Cheung, S.-H. (2004). Letter-recongition and reading speed in peripheral vision benefit from perceptual learning. Vision Research, 44, 695-709. 
Crossland, M. D., \& Rubin, G. S. (2006). Eye movements and reading in macular disease: Further support for the shrinking perceptual span hypothesis. Vision Research, 46(4), 590-597.

Dubois, M., Kyllingsbaek, S., Prado, C., Musca, S. C., Peiffer, E., Lassus-Sangosse, D., \& Valdois, S. (2010). Fractionating the multi-character processing deficit in developmental dyslexia: Evidence from two case studies. Cortex, 46, 717-738.

Ellis, A. W., \& Brysbaert, M. (2010). Split fovea theory and the role of the two cerebral hemispheres in reading: A review of the evidence. Neuropsychologia, 48(2), 353-365.

Engbert, R., Longtin, A., \& Kliegl, R. (2002). A dynamic model of saccade generation in reading based on spatially distributed lexical processing. Vision Research, 42(5), 621-636.

Engbert, R., Nuthmann, A., Richter, E., \& Kliegl, R. (2005). Swift: A dynamical model of saccade generation during reading. Psychological Review, 112, 777-813.

Ericsson, K. A., \& Kintsch, W. (1995). Long-term working memory. Psychological Review, 102, 211-245.

Flom, M. C., Weymouth, F. W., \& Kahneman, D. (1963). Visual resolution and contour interaction. Journal of the Optical Society of America, 53, 1026-1032.

Frey, A. (2016). Eye movements in children during reading: A review. In Actes du Symposium International sur la Litéracie à l'Ecole/ International symposium for educational Literacy (SILE/ ISEL) 2015 (pp. 69-90). Sherbrooke: Les Editions de I'Université de Sherbrooke.

Frey, A., Ionescu, G., Lemaire, B., Lopez-Orozco, F., Baccino, T., \& Guérin-Dugué, A. (2013). Decision-making in information seeking on texts: En eye-fixation-related potentials investigation. Frontiers in Systems Neuroscience. Research Topic on «Eye movement-related brain activity during perceptual and cognitive processing», 7, 39. Retrieved from https:// www.ncbi.nlm.nih.gov/pmc/articles/PMC3743136/

Germano, G. D., Reilhac, C., Capellini, S. A., \& Valdois, S. (2014). The phonological and visual basis of developmental dyslexia in Brazilian Portuguese reading children. Frontiers in Psychology, 5, 1169. Retrieved from https://www.ncbi.nlm. nih.gov/pmc/articles/PMC4196516/

Gleason, J. B. (2005). The development of language (6th ed.). Boston, MA: Pearson Education, Inc.

Goswami, U. (2015). Sensory theories of developmental dyslexia: Three challenges for research. Nature Reviews Neuroscience, 16(1), 43-54.

Grainger, J., Dufau, S., \& Ziegler, J. C. (2016). A vision of reading. Trends in Cognitive Sciences, 20(3), 171-179.

He, Y., Scholz, J. M., Gage, R., Kallie, C. S., Liu, T., \& Legge, G. E. (2015). Comparing the visual spans for faces and letters. Journal of Vision, 11(8), 1-13.

Henderson, J. M., \& Ferreira, F. (1990). Effects of foveal processing difficulty on the perceptual span in reading: Implications for attention and eye movement control. Journal of Experimental Psychology: Learning, Memory, and Cognition, 16, 417-429.

Huey, E. B. (1908). The psychology and pedagogy of reading. Cambridge, MA: MIT Press.
Ibrahim, R., Eviatar, Z., \& Aharon Peretz, J. (2002). The characteristics of the Arabic orthography slow its cognitive processing. Neuropsychologia, 16(3), 322-326.

Inhoff, A. W., Pollatsek, A., Posner, M. I., \& Rayner, K. (1989). Covert attention and eye movements during reading. Quarterly Journal of Experimental Psychology: Human Experimental Psychology, 41(A), 63-89.

Jordan, T. R., Almabruk, A. A., Gadalla, E. A., McGowan, V. A., White, S. J., Abedipour, L., \& Paterson, K. B. (2014). Reading direction and the central perceptual span: Evidence from Arabic and English. Psychonomic Bulletin \& Review, 21(2), 505-511.

Jordan, T. R., Dixon, J., McGowan, V. A., Kurtev, S., \& Paterson, K. B. (2016). Effects of spatial frequencies on word identification by fast and slow readers: Evidence from eye movements. Frontiers in Psychology, 7, 1433. Retrieved from https:// www.ncbi.nlm.nih.gov/pmc/articles/PMC5039934/

Jordan, T. R., McGowan, V. A., Kurtev, S., \& Paterson, K. B. (2016). A further look at postview effects in reading: An eye-movements study of influences from the left of fixation. Journal of Experimental Psychology: Learning, Memory, and Cognition, 42(2), 296-307.

Jordan, T. R., McGowan, V. A., \& Paterson, K. B. (2012). Reading with a filtered fovea: The influence of visual quality at the point of fixation during reading. Psychonomic Bulletin \& Review, 19, 1078-1084.

Jordan, T. R., \& Paterson, K. B. (2010). Where is the evidence for split fovea processing in word recognition? Neuropsychologia, 48, 2782-2783.

Kilho, S., Chung, S. T. L., \& Bosco, S. T. (2017). Crowding, visual awareness, and their respective neural loci. Journal of Vision, 17(5), 1-18.

Kliegl, R., Wei, P., Dambacher, M., Yan, M., \& Zhou, X. (2011). Experimental effects and individual differences in linear mixed models: Estimating the relationship between spatial, object, and attraction effects in visual attention. Frontiers in Psychology: Quantitative Psychology and Measurement, 1, 238.

Kwon, M., Legge, G. E., \& Dubbels, B. R. (2007). Developmental changes in the visual span for reading. Vision Research, 47, 2889-2900.

Kwon, M., Liu, R., Patel, B. N., \& Girkin, C. (2017). Slow reading in Glaucoma: Is it due to the shrinking visual span in central vision? Investigative Ophthalmology \& Visual Science, 58(13), 5810-5818.

Laberge, D., \& Samuels, S. J. (1974). Toward a theory of automatic information processing in reading. Cognitive Psychology, 3, 293-323.

Lallier, M., Abu Mallouh, R., Mohammed, A. M., Khalifa, B., Perea, M., \& Carreiras, M. (2018). Does the visual attention span play a role in reading in Arabic? Scientific Studies of Reading, 22(2), 181-190.

Lallier, M., Acha, J., \& Carreiras, M. (2016). Cross-linguistic interactions influence reading development in bilinguals: $A$ comparison between early balanced French-Basque and Spanish-Basque bilingual children. Developmental Science, 19(1), 76-89. 
Lallier, M., Valdois, S., Lassus-Sangosse, D., Prado, C., \& Kandel, S. (2014). Impact of orthographic transparency on typical and atypical reading development: Evidence in French-Spanish bilingual children. Research in Developmental Disabilities, 35 (5), 1177-1190.

Lassus-Sangosse, D., N'Guyen-Morel, M. A., \& Valdois, S. (2008). Sequential or simultaneous visual processing deficit in developmental dyslexia? Vision Research, 48, 979-988.

Legge, G. E., Ahn, S. J., Klitz, T. S., \& Luebker, A. (1997). Psychophysics of reading. XVI. The visual span in normal and low vision. Vision Research, 37, 1999-2010.

Legge, G. E., \& Bigelow, C. A. (2012). Does print size matter for reading? A review of findings from vision science and typography. Journal of Vision, 11(5), 1-22.

Legge, G. E., Cheung, S. H., Yu, D., Chung, S. T. L., Lee, H.-W., \& Owens, D. P. (2007). The case for the visual span as a sensory bottleneck in reading. Journal of Vision, 7, 1-15.

Legge, G. E., Hooven, T. A., Klitz, T. S., Mansfield, J. S., \& Tjan, B. S. (2002). Mr. Chips 2002: New insights from an ideal-observer model of reading. Vision Research, 42, 2219-2234.

Legge, G. E., Klitz, T. S., \& Tjan, B. S. (1997). Mr. Chips: An ideal-observer model of reading. Psychological Review, 104, 524-553.

Legge, G. E., Mansfield, J. S., \& Chung, S. T. L. (2001). Psychophysics of reading. XX. Linking letter recognition to reading speed in central and peripheral vision. Vision Research, 41, 725-734.

Levi, D. M. (2011). Visual crowding. Current Biology, 21(18), 678-679.

Levi, D. M., \& Klein, S. A. (1985). Vernier acuity, crowding and amblyopia. Vision Research, 25, 979-991.

Liu, D. (2014). Visual-spatial attention and its relationship with reading. In K. K. H. Chung, K. C. P. Yuen, \& D. M. Mclnerney (Eds.), Understanding developmental disorders of auditory processing, language and literacy across languages, international perspectives (pp. 169-188). Charlotte, NC: Information Age Publishing.

Lobier, M., Dubois, M., \& Valdois, S. (2013). The role of visual processing speed in reading speed development. PLOS ONE, 8, 4. Retrieved from http://journals.plos.org/plosone/article?id= 10.1371/journal.pone.0058097

Lobier, M., Peyrin, C., Le Bas, J. F., \& Valdois, S. (2012). Pre-orthographic character string processing and parietal cortex: A role for visual attention in reading? Neuropsychologia, 50(9), 2195-2204.

Lobier, M., Peyrin, C., Pichat, C., Le Bas, J. F., \& Valdois, S. (2014). Visual processing of multiple elements in the dyslexic brain: Evidence for a double dysfunction of parietal and occipito-temporal cortex. Frontiers in Human Neuroscience, 8, 479. Retrieved from https://www.ncbi.nlm.nih.gov/pmc/ articles/PMC4083222/

Lobier, M., \& Valdois, S. (2015). Visual attention deficits in developmental dyslexia cannot be ascribed solely to poor reading experience. Nature Reviews Neuroscience, 16(4), 225-225.

McClelland, J. L., \& Rumelhart, D. E. (1981). An interactive activation model of context effects in letter perception: Part
1. An account of basic findings. Psychological Review, 88(5), 375-405.

McConkie, G. W., \& Rayner, K. (1975). The span of the effective stimulus during a fixation in reading. Perception \& Psychophysics, 17, 578-586.

McConkie, G. W., \& Rayner, K. (1976). Asymmetry of the perceptual span in reading. Bulletin of the Psychonomic Society, 8 , 365-368.

Miellet, S., O'Donnell, P. J., \& Sereno, S. C. (2009). Parafoveal magnification: Visual acuity does not modulate the perceptual span in reading. Psychological Science, 20, 721-728.

Miellet, S., \& Sparrow, L. (2004). Phonological codes are assembled before word fixation: Evidence from boundary paradigm in sentence reading. Brain and Language, 90(1), 299-310.

Nation, K., \& Castles, A. (2017). Putting the learning in orthographic learning. In K. Cain, D. Compton, \& R. Parilla (Eds.), Theories of reading development (pp. 148-168). Amsterdam, The Netherlands: John Benjamins Publishing Company.

Nazir, T. A., O'Regan, J. K., \& Jacobs, A. M. (1991). On words and their letters. Bulletin of the Psychonomic Society, 29, 171-174.

Ojanpää, H., Näsänen, R., \& Kojo, I. (2002). Eye movements in the visual search of word lists. Vision Research, 42, 1499-1512.

O'Regan, J. K. (1990). Eye movements and reading. In E. Kowler (Ed.), Eye movements and their role in visual and cognitive processes (pp. 395-453). New York: Elsevier.

O'Regan, J. K. (1991). Understanding visual search and reading using the concept of stimulus "grain". IPO Annual Progress Reports, 26, 96-108.

Paterson, K. B., McGowan, V. A., White, S. J., Malik, S., Abedipour, L., \& Jordan, T. R. (2014). Reading direction and the central perceptual span in Urdu and English. PLOS ONE, 9(2). Retrieved from https://scirp.org/reference/ ReferencesPapers.aspx?ReferencelD $=1334371$

Pelli, D. G. (2009). Towards an easier way to measure the visual span. Journal of Vision, 9(8), 1002-1002.

Perea, M., Mallouh, R. A., \& Carreiras, M. (2014). Are root letters compulsory for lexical access in Semitic languages? The case of masked form-priming in Arabic. Cognition, 132(3), 491-500.

Perfetti, C. A. (2007). Reading ability: Lexical quality to comprehension. Scientific Studies of Reading, 11, 357-383.

Peyrin, C., Démonet, J. F., N'Guyen-Morel, M. A., Le Bas, J. F., \& Valdois, S. (2011). Superior parietal lobule dysfunction in a homogeneous group of dyslexic children with a visual attention span disorder. Brain and Language, 118, 128-138.

Peyrin, C., Lallier, M., Démonet, J.-F., Pernet, C., Baciu, M., Le Bas, J. F., \& Valdois, S. (2012). Neural dissociation of phonological and visual attention span disorders in developmental dyslexia: fMRI evidence from two case reports. Brain and Language, 120, 381-394.

Phénix, T., Diard, J., \& Valdois, S. (2016). Les modèles computationnels de lecture. In M. Sata, \& S. Pinto (Eds.), Traité de neurolinguistique (pp. 167-182). Louvain-la-Neuve, Belgium: De Boeck supérieur. 
Pollatsek, A., Bolozky, S., Well, A. D., \& Rayner, K. (1981). Asymmetries in the perceptual span for Israeli readers. Brain and Language, 14, 174-180.

Pollatsek, A., Rayner, K., \& Balota, D. A. (1986). Inferences about eye movement control from the perceptual span in reading. Perception \& Psychophysics, 40, 123-130.

Pollatsek, A., Reichle, E. D., \& Rayner, K. (2006). Tests of the EZ reader model: Exploring the interface between cognition and eye-movement control. Cognitive Psychology, 52(1), $1-56$.

Pomplun, M., Reingold, E. M., \& Shen, J. (2001). Investigating the visual span in comparative search: The effects of task difficulty and divided attention. Cognition, 81, 57-67.

Prado, C., Dubois, M., \& Valdois, S. (2007). The eye movements of dyslexic children during reading and visual search: Impact of the visual attention span. Vision Research, 47(19), 2521-2530.

Rayner, K. (1977). Visual attention in reading: Eye movements reflect cognitive processes. Memory \& Cognition, 4, 443-448.

Rayner, K. (1981). Eye movements and the perceptual span in reading. In F. J. Pirozzolo, \& M. C. Wittroch (Eds.), Neuropsychological and cognitive processes in reading (pp. 145-165). New York: Academic Press.

Rayner, K. (1984). Visual selection in reading, picture perception, and visual search: A tutorial review. In H. Bouma, \& D. Bouwhuis (Eds.), Attention and performance (Vol. 10, pp. 67-96). Hillsdale, NJ: Erlbaum.

Rayner, K. (1986). Eye movements and the perceptual span in beginning and skilled readers. Journal of Experimental Child Psychology, 41(2), 211-236.

Rayner, K. (1998). Eye movements in reading and information processing: 20 years of research. Psychological Bulletin, 124, 372-422.

Rayner, K. (2009). Eye movements in reading: Models and data. Journal of Eye Movement Research, 2(5), 1-10.

Rayner, K. (2014). The gaze-contingent moving window in reading: Development and review. Visual Cognition, 22, 242-258.

Rayner, K., Abbott, M. J., \& Plummer, P. (2015). Individual differences in perceptual processing and eye movements in reading. In Handbook of individual differences in reading: Text and context. New York, NY: Informa UK Limited.

Rayner, K., \& Bertera, J. H. (1979). Reading without a fovea. Science, 206, 468-469.

Rayner, K., \& Inhoff, A. W. (1981). Control of eye movements during reading. In B. L. Zuber (Ed.), Models of oculomotor behavior and control. West Palm Beach, FL: CRC Press.

Rayner, K., Liversedge, S. P., White, S. J., \& Vergilino-Perez, D. (2003). Reading disappearing text: Cognitive control of eye movements. Psychological Science, 14, 385-388.

Rayner, K., Slattery, T. J., \& Bélanger, N. (2010). Eye movements, the perceptual span, and reading speed. Psychonomic Bulletin \& Review, 17(6), 834-839.

Rayner, K., Well, A. D., Pollatsek, A., \& Bertera, J. H. (1982). The availability of useful information to the right of fixation in reading. Perception \& Psychophysics, 31, 537-550.
Reichle, E. D., Pollatsek, A., \& Rayner, K. (2006). E-Z reader: A cognitive-control, serial-attention model of eye-movement behavior during reading. Cognitive Systems Research, 7(1), 4-22.

Reichle, E. D., Rayner, K., \& Pollatsek, A. (2003). The E-Z reader model of eye movement control in reading: Comparison to other models. Behavioral and Brain Sciences, 26, 445-476.

Risse, S. (2014). Effects of visual span on reading speed and parafoveal processing in eye movements during sentence reading. Journal of Vision, 14(8), 1-13.

Sargiani, R., Maluf, M. R., \& Bosse, M.-L. (2015). O papel da amplitude visuoatencional e da consciência fonêmica na aprendizagem da leitura (The role of visual attention span and phonemic awareness in learning to read). Psicologia: Reflexão e Crítica, 28(3), 593-602.

Schad, D. J., \& Engbert, R. (2012). The zoom lens of attention: Simulating shuffled versus normal text reading using the SWIFT model. Visual Cognition, 20, 391-421.

Schotter, E. R., Angele, B., \& Rayner, K. (2012). Parafoveal processing in reading. Attention, Perception and Psychophysics, $74,5-35$

Shin, K., Chung, S. T. L., \& Tjan, B. S. (2017). Crowding, visual awareness, and their respective neural loci. Journal of Vision, 17(5), 18.

Silva, C., Faísca, L., Ingvar, M., Petersson, K. M., \& Reis, A. (2012). Literacy: Exploring working memory systems. Journal of Clinical and Experimental Neuropsychology, 34, 369-377.

Sperling, G. (1960). The information available in brief visual presentations. Psychological Monographs: General and Applied, 74(11), 1-29.

Starrfelt, R., Habekost, T., \& Leff, A. P. (2009). Too little, too late: Reduced visual span and speed characterize pure alexia. Cerebral Cortex, 19(12), 2880-2890.

Valdois, S., Bosse, M.-L., Ans, B., Carbonnel, S., Zorman, M., David, D., \& Pellat, J. (2003). Phonological and visual processing deficits can dissociate in developmental dyslexia: Evidence from two case studies. Reading and Writing, 16, 541-572.

Valdois, S., Guinet, E., \& Embs, J.-L. (2014). EVADYS, logiciel d'évaluation de l'empan visuo-attentionnel chez l'enfant dyslexique (Software for the assessment of the visual attention span of dyslexic children). Isbergues: Ortho-Editions.

Valdois, S., Peyrin, C., Lassus-Sangosse, D., Lallier, M., Démonet, J.-F., \& Kandel, S. (2014). Dyslexia in a French-Spanish bilingual girl: Behavioural and neural modulations following a visual attention span intervention. Cortex, 53, 120-145.

van den Boer, M., de Jong, P. F., \& Haentjens-van Meeteren, M. (2013). Modeling the length effect: Specifying the relation with visual and phonological correlates of reading. Scientific Studies of Reading, 17, 243-256.

van den Boer, M., van Bergen, E., \& de Jong, P. F. (2014). Underlying skills of oral and silent reading. Journal of Experimental Child Psychology, 128, 138-151.

van den Boer, M., van Bergen, E., \& de Jong, P. F. (2015). The specific relation of visual attention span with reading and spelling in Dutch. Learning and Individual Differences, 39, 141-149. 
Veldre, A., \& Andrews, S. (2014). Lexical quality and eye movements: Individual differences in the perceptual span of skilled adult readers. Quarterly Journal of Experimental Psychology, 67, 703-727.

Wei, C.-C., \& Ma, M.-Y. (2016). Influences of visual attention and reading time on children and adults. Reading \& Writing Quarterly, 33(2), 97-108.

Whitford, V., \& Titone, D. (2016). Eye movements and the perceptual span during first- and second-language sentence reading in bilingual older adults. Psychology and Aging, 31 (1), 58-70.

Whitney, C. (2001). How the brain encodes the order of letters in a printed word: The SERIOL model and selective literature review. Psychonomic Bulletin \& Review, 8, 221-243.

Whitney, D., \& Levi, D. M. (2011). Visual crowding: A fundamental limit on conscious perception and object recognition. Trends in Cognitive Sciences, 15(4), 160-168.

Woodworth, R. S. (1938). Experimental psychology. New York: Henry Holt \& Co.
Yan, M., Zhou, W., Shu, H., \& Kliegl, R. (2015). Perceptual span depends on font size during the reading of Chinese sentences. Journal of Experimental Psychology: Learning, Memory, and Cognition, 41(1), 209-219.

Yu, D., Cheung, S. H., Legge, G. E., \& Chung, S. T. L. (2007). Effect of letter spacing on visual span and reading speed. Journal of Vision, 7, 1-10.

Yu, D., Legge, G. E., Wagoner, G., \& Chung, S. T. L. (2014). Sensory factors limiting horizontal and vertical visual span for letter recognition. Journal of Vision, 9(8), 820.

Yu, D., Park, H., Gerold, D., \& Legge, G. E. (2010). Comparing reading speed for horizontal and vertical English text Journal of Vision, 10(2), 1-17.

Zhao, J., Liu, M., Liu, H., \& Huang, C. (2018). The visual attention span deficit in Chinese children with reading fluency difficulty. Research in Developmental Disabilities, 73, 76-86.

Zoubrinetzky, R., Bielle, F., \& Valdois, S. (2014). New insights on developmental dyslexia subtypes: Heterogeneity of mixed reading profiles. PloS ONE, 9(6). 